\title{
SOCIOLOGY
}

\section{The Concept of Character Assassination: A Sociological Approach}

\author{
M. M. Bondarenko \\ Taras Shevchenko National University of Kyiv, Kyiv, Ukraine \\ Corresponding author. E-mail: coltbond@i.ua \\ Paper received 01.12.20; Accepted for publication 12.12.20.
}

https://doi.org/10.31174/SEND-HS2020-243VIII43-12

\begin{abstract}
Character assassination, a reputation-damaging manipulative technology, is closely analyzed and categorized in this article. A theoretical basis for representation of this concept in the sphere of sociology is proposed. The approach argues that the use of communication models and interaction theories creates a way for character assassination to be traced and examined with the help of sociological methods. Consequently, several structural forms for analysis of character assassination are presented, but not limited to the suggested sets of questions as the flexible sociological methodology allows to study the concept from different angles while mixing various theoretical approaches.
\end{abstract}

Keywords: character assassination, reputation, public image, interaction theories, sociological methods, measurement.

Introduction. Reputation has become a significant part of one's public profile, whether the one is a person, company, institution or another entity that somehow represents itself to the audience. For the public figures, the expertise in reputational risks management, communication strategy and branding, where all three fight for their image, is in demand. Same goes for the electoral process and politics as they are: political leaders and political parties have to survive in the reputational warfare every day, hour and minute. They struggle each other to get more ratings to themselves and destroy their opponents. But for the most part it is still unclear what statements, regarded as reputationdamaging, are based on facts, and what are not. That is why an important question of how to "catch", distinct, categorize and measure these attack attempts, arises.

Brief overview of related publications. The concept of character assassination is to be mentioned when it comes to the discussion of reputational damage. Character assassination (simplifying: destruction of reputation), has been used as a practice even in Ancient Times, though the attempts to conceptualize had only started in the middle of XX century, and as an academic topic, it was first introduced in 1950 by Jerome Davis in his works about negative political campaigns. Now, research tanks, such as Character Assassination and Reputation Politics Research Lab (E. Shiraev, M. Icks, S. Samoilenko, J. Keohane, J. J. Smart) work on the further academic development of this concept, especially in the field of politics, supplemented by the knowledge in the field of social psychology (A. Phelps), yet, in sociology, the concept of character assassination is seemingly new, but corresponding closely with the topics of communication processes and models (E. Goffman, H. Lasswell, D. McQuail). That is why the focus of this research paper would fall not only on the concept of character assassination itself, but also on the sociological approach of understanding this concept, especially on the ways to trace, fixate and measure it, followed by the objective of this paper: to define the theoretical and methodological specifics of sociological approach to studying the concept of character assassination.

Materials and methods of the research are based on complex systematic, structural and comparative interdisciplinary approaches, connecting the knowledge from the fields of political science, social psychology and sociology. Communication models, along with concepts of "strategic interaction" and "social dramaturgy", create the link to presenting methods, such as case study, content analysis, visual analysis and other quantitative and qualitative additional techniques, as ways of sociological analysis of character assassination.

Results and discussion. According to Sergei Samoilenko, the concept of character assassination is defined as "a deliberate and sustained effort to damage the reputation or credibility of an individual, ... social groups, institutions, and corporations, which could all experience loss of reputation" [1, p. 115]. The definition might sound similar to another concepts of negative campaigning, such as "kompromat", "labelling" and even "black" - or "negative" - PR, yet it has at least one significant difference. Apart from the other listed concepts, which may not have any factual ground under itself, character assassination bases on certainly known facts and information [2, p. 219].

Character assassination may be categorized in several types. Due to the reasons and the purpose of it, American researchers Martijn Icks and Eric Shiraev present a classification of types of character assassination [3], which include:

- anonymous lies (falsification of biographical facts);

- misquoting (omitting details from the context of one's quote);

- $\quad$ silencing ("erasing" the opponent from collective memory);

- $\quad$ acts of vandalism (performed on objects symbolizing the victim);

- name-calling (the usage of short negative labels, i.e. "terrorist", "communist");

- appellation to mental illness (stigmatization of psychological disorders);

- appellation to sexual deviations (allegations of sexual misconduct).

Such a classification rises a question of the social, even rather than political and psychological, nature of character assassination, as it calls to different sociological categories, and different levels of impact - from individual, micro level to collective, macro level - and analysis, resulting in 
the interest in formalizing the concept through the prism of sociology.

The psychological approach to conceptualization of character assassination gives the prerequisite and ground to the application of sociological point of view to the problem. For example, American scholar Andrew Phelps states that "structurally, a character assassination requires for its commission three parties, the character assassin or agent, the public whose estimation is to be altered or audience, and the person targeted or victim" [4]. This structure is partly reminiscent of sociology-based communication models, consisting of the transmitter, the medium, the receiver/audience and the effect [5], as well as of Erving Goffman's "social dramaturgy" [6] and "strategic interaction" [7] concepts, giving an ability to consider sociological approach to character assassination as relevant. For instance, the "social dramaturgy" [6] is based on several structural elements:

- $\quad$ belief in the role played (the role of the "character assassin");

- the "mask", which is a standard way for an actor to control what their audience sees (however, in this case, this mask is put on the victim as well);

- dramatic implementation as an image of the actor that they want the audience to acknowledge (and the image of the victim's "shameful" features);

- idealization, because the performance shows an idealized view of the situation in order to avoid confusion (misinterpretation) and reinforce other elements of the imagination;

- $\quad$ expression control (the actor must be sure in sending the right signals to their audience);

- misconceptions that threaten to launch the wrong message as the audience perceives the performance to be sincere or false, and the actor ("character assassin") accordingly seeks to convince viewers of the truthfulness of the idea (regardless of whether it actually is or not);

- mystifications, such as hiding specific information to increase the public interest in the actor/victim or the performance.

As for the "strategic interaction", being a set of constraints, structured choices, "moves" and internal factors [7], such interaction creates the basis for a system of coercion and control. This control also covers the field of "reputation of the individual". But this reputation is local and situational, it can change, because it is based on the expectations of a particular group. In some cases, an individual has a "right for mistake", but in many cases those mistakes (for example, FBI agents who have lost cover or political actors misbehaving in public) are difficult or even impossible to correct [7, p. 35-46]. Character assassination can be equated with social death of an individual, since the moral harm caused by the condemnation of certain actions can be irreparable [1, p. 115] and lead to the lifetime stigmatization.

Additionally, character assassination is achieved through the forms of verbal and non-verbal attacks, including language images, rumors, announcements, brochures, caricatures, all of which are broadly used in a sociological analysis. The arsenal of sociological methods of analyzing visual and non-visual information may enable a broader coverage of this concept and demonstrate its social impact.
That is why it is important to discuss the measurement methodology of character assassination.

Negative campaigning scholars Dolezal, Ennser-Jedenastik and Müller, base their research on a method of content analysis of party press releases. They emphasize that "direct control of the sender" and "represent[ing] a ... campaign strategy" [8, p. 672] are the key pros of using this method in the analysis of character assassination, for instance, in politics. According to that, during sociological research, especially during content analysis, several methodological techniques to the fixation and measuring of character assassination could be applied.

As the basis of character assassination is the concept of "negative campaigning", at first, it is worth noting that the empirical indicators of the fixation of this concept can be determined by the affiliation of research materials to the type of advertising [9]:

- aggressive advertising (which is specifically aimed at undermining reputation);

- $\quad$ contrast advertising (illuminates the desired agent in as "good" against the negativity of the opponent/victim).

Given this, and continuing with content analysis categorization, it is advisable to view character assassination through the prism of advertising practices. Accordingly, categorization and subcategorization may, for example, result in answers to such questions: What is the sphere of this given character assassination? Who/what is the purpose of attack on reputation? What/who does the message appeal to? What is the reason for the attack?

Another method that can be used is the visual analysis [10], an analytical conclusion at several levels of both visual and identification of the researched subject or material:

- $\quad$ discursive analysis (of the situation);

- hermeneutical analysis (interpretation of authorship, public position, purpose, prejudices, stereotypes, applied fields, etc.);

- hermeneutics of the image itself (heroes, attitude to the author, actions);

- $\quad$ semiotic analysis (external and internal, visible and hidden symbols);

- $\quad$ structural analysis (norms, ideas, values).

This method makes it possible to analyze each of the visual materials of character assassination individually and to draw a general conclusion about the contents of such materials on a specific topic, period or campaign.

The listed methods could be easily used during the analysis of character assassination, but their list is not limited by those descripted above. As qualitative sociological methods are flexible, there are a lot more of them to apply to the research (for example intent analysis, grounded theory, focus groups). Depending on the purpose of the study and researchers' interests, mixed methodology could also be used, as sociology, being the multiparadigmal science, can provide a lot of "supporting roles" and "focuses of view" for and with different methods.

Conclusion. Character assassination is as "a deliberate and sustained effort to damage the reputation or credibility of an individual, social groups, institutions, and corporations, which could all experience loss of reputation". Due to the reasons and the purpose of it, it can be classified to several types, such as anonymous lies, misquoting, silencing, acts of vandalism, name-calling, appellation to mental 
illness or sexual deviations. The social psychology approach to conceptualization of character assassination gives the prerequisite and ground to the application of sociological approach to this concept. Among the key sociological theories applicable to character assassination concepts are the communication models, "social dramaturgy" and "strategic interaction". Character assassination is achieved through the forms of verbal and non-verbal forms which are broadly used in a sociological analysis. Several methodological techniques to the fixation and measuring of character assassination could be applied. They include the method of content analysis, resulting in categorization of research materials to the type of advertising (aggressive or contrast) and answers to specific questions about the form and purpose of character assassination. Visual analysis is also an applicable method, which results in discursive, hermeneutical (context and image), semiotic and structural subanalysis. The number of methods to use is not limited because sociology regards qualitative analysis as flexible. Thus, the prospects for character assassination further conceptualization in the field of sociology are significant. The sophisticated sociological methods and developed theoretical approaches will allow to comprehensively study this concept at various levels, from micro to global, and to focus on its social impact, predicting its consequences for different societies.

\section{REFERENCES}

1. Samoilenko, S. Character assassination // The SAGE Encyclopedia of Corporate Reputation, ed. C. Carroll. SAGE Publications, 2016. Vol. 1. P. 115-118.

2. Smart, J. J. West versus East, or somewhere in between: how to understand cooperative times in United States - Russian relations // Revista de Filozofie, Sociologie şi Ştiinţe Politice, 2016. Is. 3(172). P. 213-221.

3. Icks, M., Shiraev, E. Character Assassination throughout the Ages. Palgrave Macmillan US, 2014. 283 p.

4. Phelps, A. The Social Psychology of Character Assassination (Alterations of Cognitive Factors Due to Deliberate Destruction of Reputation) [Senior Project Paper]. U.C. Berkeley Psychology Dept., 1977. Retrieved from http://batstar.net/piper/char.htm

5. McQuail, D. McQuail's Mass Communication Theory ( $6^{\text {th }}$ ed. $)$. SAGE, 2010. $632 \mathrm{p}$.

6. Goffman, E. The Presentation of Self in Everyday Life. Doubleday, $1959.259 \mathrm{p}$.

7. Goffman, E. Strategic Interaction. University of Pennsylvania Press, 1971. $160 \mathrm{p}$.

8. Dolezal, M., Ennser-Jedenastik, L., Müller, W. C. Who Will Attack the Competitors? How Political Parties Resolve Strategic and Collective Action Dilemmas in Negative Campaigning // Party Politics, 2017. Is. 23(6). P. 666-679.

9. Fridkin, K., Kenney, P. J. Do Negative Messages Work?: The Impact of Negativity on Citizens' Evaluations of Candidates // American Politics Research, 2004. Is. 32. P. 570-602.

10. Sztompka, P. Visual Sociology // International Encyclopedia of the Social \& Behavioral Sciences ( $2^{\text {nd }}$ Edition $)$, ed. J. D. Wright. Elsevier, 2015. P. 191-196. 